\title{
Spatial and temporal variation in flooding of rural floodplain farming areas in the Okavango Delta, Botswana
}

\author{
C. Molefe ${ }^{1}$, L. Cassidy ${ }^{2}$, L. Magole ${ }^{1} \&$ M. J. Chimbari ${ }^{3}$ \\ ${ }^{I}$ Okavango Research Institute, University of Botswana, Botswana \\ ${ }^{2}$ Ecosurv Environmental Consultants, Botswana \\ ${ }^{3}$ University of KwaZulu-Natal, South Africa
}

\begin{abstract}
The Okavango Delta is subject to annual and inter-annual inundation of varying magnitude. The inundation impacts on livelihoods of communities reliant upon the Delta for subsistence. One such livelihood option is flood recession (molapo) farming. Flood recession farming contributes substantially to rural livelihoods, however communities are faced with many challenges, particularly the unpredictability and unreliability of flooding. The study sought to determine the spatial and temporal variation in flooding that has occurred in the floodplains. Nine Landsat images were analysed. The analysis covered the period 1989 to 2008, it focused on three flood seasons each 10 years apart. The study took place in three villages on the peripheries of the Delta. Results show that the three study villages not only have very different floodplain lands available, but they also show different flooding patterns. The implication of this is that for both farmers and planners, it is not possible to have a single, blanket response to Delta flood inflows. Research outputs need to be communicated at the village level so that people can better accommodate the variation experienced where they live.

Keywords: Botswana, Okavango Delta, remote sensing, flood mapping, flood recession farming, Okavango River Basin, Landsat imagery, Tasseled Cap, band ratio, band 6 threshold.
\end{abstract}

\section{Introduction}

The inland Okavango Delta is fed by the Okavango River, which originates in Angola, and is fed by rainfall in the country's eastern highlands. Due to the large 
distance from the source area (Figure 1), the peak of the flood passes through Mohembo in April, 6-7 months after the onset of the rainy season in Angola. Rainfall in the Okavango Delta region occurs in summer, from December to February, and the discharge of the Okavango River at Mohembo (border of Botswana and Namibia) starts immediately after the wet season, usually from April. The flood waters continue to spread through the Delta's shallow river channels, spilling out onto the adjacent floodplains. The floods then arrive at the distal end of the Delta fan in the Thamalakane River four months later after the first discharge in Mohembo. Hence the maximum spatial extent of the flood waters is reached in August during winter [1]. The area covered by water expands from its annual low of 2,500-4,000 $\mathrm{km}^{2}$ in February-March to its annual high of 6,000$12,000 \mathrm{~km}^{2}$ in August-September [2].

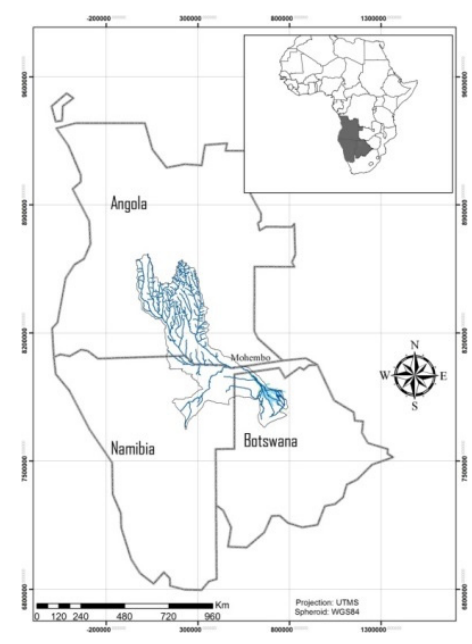

Figure 1: The Okavango river basin.

The Okavango Delta can be subdivided into two regions basing on the duration of flooding. The first region is the panhandle which is dominated by meandering river systems. This region of the Delta is relatively narrow and major river channels meander down a widening flood plain. The region between the top part of the panhandle and its middle is characterised by permanent swamp environment. From the middle of the Delta downward the area is characterised by seasonal swamps, dry grass and woodland environments which fringe the channels of the middle panhandle [3].

Towards the south end of the panhandle a number of distributaries develop that carry water to the rest of the Delta. In the west the Thaoge diverges from the Okavango River, it supplies water towards the western margins of the Delta [4]. The Jao-Boro carries water to the middle parts of the Delta and the Nqoga carries water to the eastern parts of the Delta [5]. A major split occurs in the Nqoga at the Hamoga Island. Flow in the eastern parts of the Delta is the carried by small distributory channels. The Maunachira then rises in this region. Flow from the 
Maunachira is carried to the Dxherega lediba (which is a large lagoon) when the sedimentary bed load is deposited. Below the Dxherega lediba the Maunachira joins a large channel called the Kiandiandavhu [4]. This region of the Delta is called the Upper Fan [3] with its main channel being the Nqoga and Thaoge, JaoBoro being distributaries from its right bank.

Flooding of the Okavango Delta creates a wetland ecosystem that contrasts strongly with the surrounding rain-fed semi-arid savannah of the Kalahari [6]. The Delta is subject to inundation of varying magnitude, seasonality and inter-annual variability. The cyclic behaviour of the inundation process impacts on livelihoods of communities reliant upon the Delta for subsistence including flood recession farming [7]. Flood variability is the most important factor in determining the extent to which flood recession (molapo) farming is practiced [8]. Because of the substantial contribution that molapo farming can make to rural livelihoods, it is important to understand how variability in inundation affects the farming system.

\section{Material and methods}

The study used remote sensing and geographic information system related technology to collect and analyse data. The best available Landsat images were obtained from the United States Geological Survey's (USGS) web site. Nine Landsat images across two scenes (p174r074 and p175r073) were analysed covering the period 1989 to 2008.

All image processing was performed in Erdas Imagine and ArcGIS software. The images were subjected to radiometric and atmospheric calibration. Radiometric and atmospheric calibration for the visible bands allows features of an image to be linked to a particular land cover by converting the recorded digital number to the surface reflectance value associated with a particular land cover. Such calibration is necessary to correct for a) platform 'slippage' over time, and b) variations in atmospheric interference, so that the spectral signals can be standardised for comparison across time. The images were then geometrically corrected using image to image rectification, to ensure that they were accurately aligned with each other. This ensures that any change assessments are due to real variation in spectral signatures between different time-steps, and not due to misalignment and differences being due to different areas covered by the image. About 50 ground control points were collected for each image. Orthorectified Landsat images acquired from the Global Land Cover Facility of the University of Maryland were used for as the base image for geo-registration. Nearest neighbour method were used in the re-sampling, with an output pixel size of $30 \mathrm{~m}$. From each georectified image the root mean square error (RMSE) was reduced to 0.05 of a pixel, to ensure as close possible spatial alignment between the timesteps and so minimise error when assessing change over time [9].

\subsection{Image processing for flood data derivation}

In the Okavango Delta, flood waters are covered by riparian vegetation. The floods spread across occasional floodplains resulting in shallow waters. The area is also 
prone to seasonal wild fires. The characteristics of the flood pulsed system, make it problematic to derive flood information from satellite imagery. Burnt areas and water have the same signal numbers in satellite images, the vegetated water also hinders water signal from reflecting hence mostly vegetation signal will be reflected. The challenges in mapping flood plain waters have also been noted by researchers in Cambodia [10]. It was noted that due to the problematic nature of inundation mapping in flood plain environments, methods of mapping should incorporate the use of a ratio of mid-infrared reflectance to a visible band reflectance. Hence these techniques help to deal with shallow water problems.

In view of the fact that inundation mapping can be problematic in flood plain areas, this study employed an approach developed by [11] to determine the flooded area for each time-step. Nine images from three years $(1989,2001$ and 2008) and two scenes (p174r074 and p175r073) were used in flood mapping. Although all the data required was not readily available, it was ensured that dates on selected images were closest to the maximum flood event in all the years for each study site.

The approach of [11] used the combination of Tasseled Cap Analyses, band 6 thresholding and band ratio-ing of bands 5and 2 to derive the flood maps for each study site, as described below.

\subsection{Tasseled cap transformation}

Firstly a Tasseled Cap Analysis was done for each image. Tasseled Cap Transformation was firstly developed by Kauth and Thomas [14], mainly for vegetation studies. The first application of a Tasseled Cap Transformation was done on Landsat MSS, where the four band of the MSS data were scaled down so as at to view the data in a three dimensional plane. The planes used to view the data were interpreted as the soils plane, greenness plane and yellowing plane [15, 16]. This transformation was used to track the development of crops. The data was presented in a curving trajectory which was triangular - or cap-like - in shape [14]. In its current application, through a weighted computation it scales down the six bands of Landsat images to three bands: brightness, a measure of soil; greenness, a measure of vegetation; and wetness, the interrelationship of soil and canopy moisture [17]. Tasseled Cap Transformation is mainly used in vegetation studies to establish biomass or change. Tasseled Cap Analysis can also be used to pull out degrees of wetness in images. Hence in this study the Tasselled Cap Transformation was used to delineate flood extent boundary. Here, the output image layer of interest is the third Tasselled Cap band, relating to wetness.

\subsection{Band ratio-ing}

Next, ratios of bands 5 and 2 were derived. Band ratio-ing is a process that divides pixel values of one band by pixel values of another band. Deriving band ratios provides unique information depending on the bands used to perform the ratio. Band $5(1.55-1.75 \mu \mathrm{m})$ is sensitive to the amount of water in plants. It can be used to distinguish between trees and herbaceous plants while band $2(0.52-0.60 \mu \mathrm{m})$ is sensitive to vegetation reflectance as this wavelength range covers the green 
reflectance peak from leaf surfaces; it also sensitive to turbidity in water bodies. Thus pixels with a high ratio are likely to highlight wetland areas or water bodies while pixels with low ratio values are likely to show vegetation.

The output from the ratio is an image layer that distinguishes vegetation reflectance from that of water bodies, as it makes it easier to distinguish between water in plants, open water and vegetation.

\subsection{Thresholding of band 6}

Thresholding was done to mask out hot areas from cool areas. Landsat's band 6 $(10.40-12.50 \mu \mathrm{m})$ is an emittance band, capturing surface temperature of the earth's surface. The distribution of the pixels in band 6 seemed to suggest that areas below $25^{\circ} \mathrm{C}$ were wet areas and those above were dry. There was a sudden drop in the histogram at $25^{\circ} \mathrm{C}$ as the brightness of pixels was increasing. So the following model was used to set the threshold:

EITHER 1 IF (\$n1_p174r074_19890904_tm5_calib_vir_thr_georec(6) < 25) OR 2 OTHERWISE

The thresholding resulted in an output image layer with two classes, where 1 was a class of cooler wet areas, and 2 a class of hotter dry areas.

\subsection{Derivation of wet-dry areas}

Derivation of wet and dry areas was done for the three years representative of different flood phases (1991 - declining flood phase, 2001 - dry phase, and 2008 - wet phase). Tasselled Cap Analysis, Band ratio-ing and thresholding of band 6 all had a single layer output. The resulting three layer files were then classified into wet/dry, using unsupervised two classes, with twenty iterations, Interactive Self-Organizing Data Analysis Technique (ISODATA) classification procedure.

Accuracy of the wet-dry images was done based on ground control points collected for the most recent time step because images used dated back in time hence the inability to go back in time to collect ground control points. The total producer's accuracy was not less than $95 \%$.

\subsection{Study villages}

The study was conducted in three villages on the fringes of the Okavango Delta where farming is practised. These are: Tubu, located to the west of the Delta on the Thaoge river channel; Shorobe, which is situated on the Thamalakane river at the south-eastern end of the Delta; and Xobe on the Boteti channel. The villages were selected on the basis of their different locations, and because of variations in their floodplain conditions. The molapo floodplain areas in all study sites get moisture as the floods rise and peak. However the timing for the peak is different, with Tubu reaching its peak a few months before Shorobe and Xobe. Xobe's floodplains are confined within shallow channel banks, limiting the area available for molapo farming.

Study site boundaries for each community were identified with the communities during field visits. Although the villages do not have any official 
administrative boundaries, these study site areas represent a good approximation of the sphere of influence of each community, incorporating much of the dry land fields and grazing areas that they access under Botswana's communal land tenure system.

\section{Results}

\subsection{Flooded areas}

The change in extent and distribution of floodwaters varied considerably at each site with different responses at the three time-steps. The extent of inundated floodplains for each study site is shown in (Table 1). There was a little decrease in Tubu during the dry flood phase and a slight increase in the high flood phase with an increase in flooding Shorobe during the wet phase, and only some increase in Xobe during the recent return to high flood levels.

Table 1: Total flooded area in hectares (ha) for imagery representing each of the different time-steps of interest.

\begin{tabular}{|c|c|c|c|c|}
\hline $\begin{array}{l}\text { Flood } \\
\text { Phase }\end{array}$ & Year & Tubu & Shorobe & Xobe \\
\hline Medium & $\begin{array}{c}1989 \\
\text { (1 year prior to field map date) }\end{array}$ & 38974.6 & 2650.8 & 197.3 \\
\hline Dry & $\begin{array}{l}2001 \\
\text { (1 year prior to field map date) }\end{array}$ & 37772.6 & 324.3 & 179.1 \\
\hline Wet & $2008^{*}$ & 33142.9 & 3304.6 & 160.4 \\
\hline
\end{tabular}

*2008 is used to represent 2010/2011 because Landsat TM 5 imagery for September after that date was not available during the time of this study.

It is notable that only Shorobe flooded areas seem to be synchronised to the overall flood phases of the Delta. In contrast, Tubu and Xobe had their greatest extent flooded during the medium phase, suggesting that the relationship between inflow phase and the distribution across the floodplains differs for the three study areas. This is particularly true when looking at the dry flood phase, where Tubu's floodplain area decreased by only $3.1 \%$, while Shorobe's decreased strongly by $87.8 \%$ and Xobe's by $9.2 \%$.

In Tubu, there appears to be a decrease in flood extent, as well as consolidation of flooded areas, between 1989 and 2001. This is particularly noticeable on the north western branch of the Thaoge River. In 2008, the flood area is again reduced, but it remains much more consolidated, and not as spread out.

Shorobe flood phase reflected that of the entire Delta. In 2001 floodplains were almost dry, with only a small amount of area receiving inundation. In 2008 there was a return of a high flood with previously dry areas in the Northern part receiving flood waters. There was less variation in inundation for Xobe between the three flood phases as evident in the flood maps. 


\subsection{Wet and dry trajectories}

A comparison of these flooding trajectories suggests that the conditions in the floodplains of the three study villages respond very differently to the different flood phases, regardless of the floodplain extent available. Of the three villages, Tubu appears to have the greatest proportion of its floodplains tending to dry at the last time-step, while Xobe's is the most stable. Shorobe's floodplains also appear to be constant and having more land inundated in the last time-step.

The wet and dry trajectories for Tubu village show (Figure 2) that there was a large amount of area at $18 \%$ that changed from dry to wet then wet again. The trend of dry-dry-wet dominates the patterns of change for Shorobe floodplains (Figure 2). Notably, the next largest class is also a transition from dry to wet. The initial change from wet to dry takes place during an overall dry phase in the Okavango, suggesting that there is considerable variation at the local level. The steep bank of the Boteti River channel explains why there is less variation in the spatial extent of flooding for Xobe.
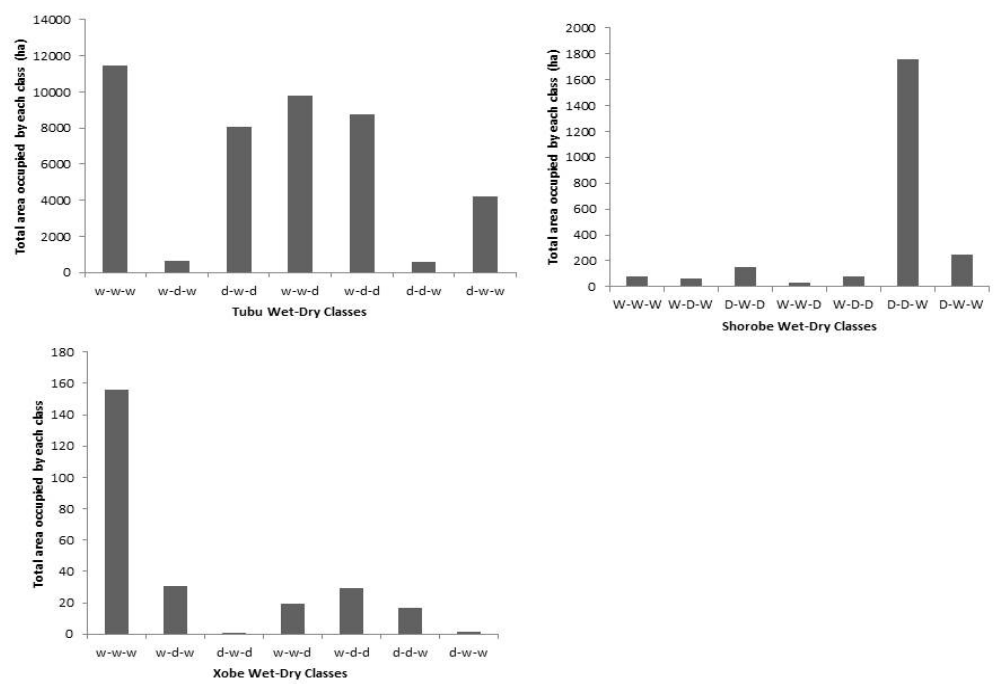

Figure 2: Histograms showing wet and dry trajectories for three villages.

\section{Discussion and conclusions}

Channels of the Okavango Delta have over time been changing. For example the Thaoge used to feed Lake Ngami. However the Thaoge dried out and the water was redirected to the Nqoga channel. The Nqoga was also blocked over time leading to the development of secondary channels to carry water. Results of this paper emphasize this dynamism of the Okavango Delta.

The three study villages not only have very different amounts and kinds of floodplain lands available, but they also show different flooding patterns at each 
one of the three time-steps. It is important to note that only Shorobe follows the same wet-dry trend as the overall Delta, moving from dry in the early 2000s to wet in 2010, while those of Tubu and Xobe seem to follow an opposite trend.

While it is well established that the flooding of the entire Okavango Delta is highly variable [7], this study suggests that the overall patterns of flooding do not always hold true at more localised levels, and that using Mohembo inflow data only does not always predict the situation for individual floodplain areas. Thus, while even at small scales the variability and unpredictability of flooding extent applies, the way in which the floods vary differs from place to place. There is no one trend that can be used to describe flooding of the Okavango Delta at the local scale.

The implication of this is that for both farmers and planners, it is not possible to have a single, blanket response to Delta flood inflows. Instead, monitoring and decision making need to be made at the village level so that people can better accommodate the variation experienced where they live. In order to provide better predictability to the local level, further studies should look at the long-term relationships between Mohembo inflows and the spatial distribution of floodwaters at each of the three different communities.

\section{References}

[1] Ellery, W.N. and T.S. McCarthy, Principles for the sustainable utilization of the Okavango Delta ecosystem, Botswana. Biological Conservation. 70: pp. 159-168, 1994.

[2] McCarthy, J.G., et al., Flooding patterns in the Okavango wetland in Botswana, between 1972 and 2000. Ambio: A journal of the human environment. 32(7): pp. 453-457, 2003.

[3] McCarthy, T., A. Bloem, and P. Larkin, Observations on the hydrology and geohydrology of the Okavango Delta. South African Journal of Geology. 101: p. 2, 1998.

[4] McCarthy, T., I. Stanistreet, and B. Cairncross, The sedimentary dynamics of active fluvial channels on the Okavango fan, Botswana. Sedimentology. 38(3): pp. 471-487, 1991.

[5] McCarthy, T. and W. Ellery, The Okavango Delta. Transactions of the Royal Society of South Africa. 53(2): pp. 157-182, 1998.

[6] Wolski, P. and H.H.G. Savenije, Dynamics of floodplain-island groundwater flow in the Okavango Delta, Botswana. Journal of Hydrology. 320(3-4): pp. 283-301, 2006.

[7] Mazvimavi, D. and P. Wolski, Long-term variations of annual flows of the Okavango and Zambezi Rivers. Physics and Chemistry of the Earth. 31(1516): pp. 944-951, 2006.

[8] Kgathi, D.L., G. Mmopelwa, and K. Mosepele, Natural resource assessment in the Okavango Delta, Botswana: Case studies of some key resources. Natural Resource Forum 29: pp. 70-81, 2005. 
[9] Bakker, W.H., et al., Principles of Remote Sensing K. Tempfli, et al., Editors., The International Institute for Geo-Information Science and Earth Observation (ITC): Enschede, The Netherlands, 2009.

[10] Benger, S.N., Remote Sensing of Ecological Responses to Changes in the Hydrological Cycles of the Tonle Sap, Cambodia.

[11] Wolski, P. and M. Murray-Hudson. Reconstruction 1989-2005 inundation history in the Okavango Delta from archival Landsat ${ }^{\mathrm{TM}}$ imagery. In GlobWetland symposium. Frascati, Italy, 2006.

[12] McCarthy, T.S., et al., Seasonal flooding in the Okavango Delta, Botswana recent history and future prospects. South African Journal of Science. 96: pp. 25-33, 2000.

[13] Sanyal, J. and X.X. Lu, Application of Remote Sensing in Flood Management with Special Reference to Monsoon Asia: A review. Natural Harzards. 33: pp. 283-301, 2004.

[14] Kauth, R.J. and G.S. Thomas, The Tasselled Cap - A Graphic Description of the Spectral - Temporal Development of Agricultural Crops as Seen by LANDSAT, in LARS Symposia. The Institute of Electrical and Electronics Engineers, Inc.: Purdue University: Indiana, 1976.

[15] Crist, E.P. and R.C. Cicone, A physically-Based Transformation of Thematic Mapper Data - The TM Tasseled Cap. Transactions on geoscience and remote sensing. GE-22(3), 1984.

[16] Crist, E.P. and R.J. Kauth, The Tasseled Cap De-Mystified. Environmental Research Institute of Michigan, 1986.

[17] Jensen, J.R., Introductory Digital Image Processing. 2005. 